\title{
RESTORATION BENEFITS TO NATURAL SPRINGS IN THE LAKE MARY WATERSHED
}

\author{
Clairisse Nash ${ }^{1}$, Aregai Tecle ${ }^{1}$, Ashley Craig ${ }^{1}$, Andrew Sanchez-Meador ${ }^{1}$, and Larissa Yocom ${ }^{1}$
}

Hoxworth Springs are one group of the many natural springs located in the Lake Mary watershed of northern Arizona. They are a part of and located in the Coconino National Forest's ponderosa pine type forest at an elevation of 2,143 $\mathrm{m}$ and about 12 miles to the southwest of the City of Flagstaff, Arizona. The springs are an important source of fresh water in the Lake Mary watershed area. Based on evidence such as fire scars on trees, researchers have determined the pre-settlement reference conditions for the ponderosa pine forests in the area. Prior to pre-settlement, the forest stands in the area experienced frequent and low-intensity fire regimes that supported healthy understory vegetation with a lower risk of erosion (Cocke et al. 2005). The ponderosa pine trees were characterized as, "extremely well-spaced and commonly forming a very open forest," (Weaver 1943). The reference conditions of the springs were found to have had "... pools of water along narrow streams and fertile soils...," with, "good meadow and knee-deep grama grasses ..." (Stevens 2010).

The areas around Lake Mary and the nearby Mormon Lake were used extensively as local sources of water by early Mormon settlers and the Hopi, Navajo and Moenkopi peoples in the mid1800 s. Since then, the areas have become heavily settled and used for grazing, hunting and recreation. Within 20 years of the Homestead Act of 1862 and the completion of the railroad in 1888, the same area became overcrowded with more competition for fresh water (Brown 2008). The increased grazing and other heavy resources uses along the fragile streams have made the Lake Mary watershed more susceptible to increased risks of degradation.

Riparian and wetland habitats are of immense value to the Southwest, as they are highly productive systems characterized by good quality water, reliable forage for herbivores, and with high diversity of flora and fauna (Medina 1996, Phillips 2006). Functions of a healthy riparian system include: maintaining stable stream banks, good quality water, high water table, high biomass production, deep soil organic matter content, and perennial vegetation types. Wetlands are also characterized by certain vegetation types such as native aquatic or mesic vegetation types, for example, Carex spp. However, these valuable, biological "hot spots" are often found in degraded areas (Medina 1996). Disturbance events such as floods and fires have certain effects on wet meadow habitats, however, the most impacts come from human and animal activities such as constructing roads, recreation activities, grazing and trampling (Medina 1996). Although wetlands can function at various conditions, ecosystem services such as water purification and support for biodiversity are at risk of being lost due to continued grazing, off-road motor vehicle recreation, erosion, sedimentation, loss of water retention and catastrophic wildfire.

Soil erosion is the process of soil materials leaving a system. This is a major problem along stream banks of rivers, their channels, and in springs that are particularly susceptible to erosion by stream flows. Stream banks tend to loose stability over time as a result of compounding vegetation loss along the banks, flood disturbance events, and continued grazing and other activities of ungulates (Medina 1996). As stream banks erode away, the stream structure gets wider and shallower over time, reducing the flow to downstream locations and decreasing the wet meadow's ability to support aquatic life or to function as a source of fresh water supply for mammals, birds, insects, amphibians, and other animals. Furthermore, sedimentation and "silting" occur in downstream areas as sediments flow from eroded areas along the stream. This results in reduction in water storage capacity and additional alteration of stream morphology. Soil erosion can also result in loss of soil stability and productivity. Subsequent changes in plant community structure can also change the quantity and quality of stream flow and the physical structure of the stream (Baker 2003). Furthermore, invasion by annual grasses may result in the loss of mosses and soil bio crusts, which are important soil stabilizers (Belnap 2003).

To address concerns of soil erosion along Hoxworth Springs and other areas of the Lake Mary watershed Springer et al. (2005) did some restoration activities that improved the conditions of this wet meadow system. The efforts consisted of stream channel stabilization in 1997 and in 1998, followed by re-vegetation within the next few years. The restoration activities included use of netting for soil stabilization and planting by transplants and directseeding (Springer et al. 2005). An elk exclosure fence was installed around the spring's source in what is known as "Phase I" to protect the newly treated areas from further impacts by grazing animals. The stream flow after restoration, in September

${ }^{1}$ School of Forestry, Northern Arizona University in Flagstaff, AZ 
of 2004, was measured to be approximately $0.2-0.3$ gallons per minute (Springer et al. 2005). The restoration area is currently closed to motor vehicles, using elk exclosure, though there is a large gap in the fence that appears to have been created with wire cutters. The community of Elk Park Meadows is located very close to the springs, and the area has been is used for local recreational purposes.

The primary objective of this study is to determine if the restoration efforts by Springer et al. (2005) had a positive effect on the overall health of the wetland system created by Hoxworth Springs. To achieve the objective, we asked the following questions: 1) Does the restoration effort improve soil stability? 2) Is the vegetation cover along the stream adequate and appropriate? 3) Do spring restoration efforts decrease stream width? Based on these questions, the research hypotheses related to the above questions are expressed, respectively, as:

$\mathrm{H}_{\mathrm{o} 1}: \mu \mathrm{SAG}_{1}=\mu \mathrm{SAG}_{2}$ vs. $\mathrm{H}_{\mathrm{a} 1}: \mu \mathrm{SAG}_{1}>\mu \mathrm{SAG}_{2}$, at alpha $=0.05$.

$\mathrm{H}_{\mathrm{o} 2}: \mu \mathrm{VC}_{1}=\mu \mathrm{VC}_{2}$ vs. $\mathrm{H}_{\mathrm{a} 2}: \mu \mathrm{VC}_{1}>\mu \mathrm{VC}_{2}$, at alpha $=0.05$.

$\mathrm{H}_{\mathrm{o} 3}: \mu$ Width $_{1}=\mu$ Width $_{2}$ vs. $\mathrm{H}_{\mathrm{a} 3}: \mu$ Width $_{1}<\mu$ Width $_{2}$, at alpha $=0.05$.

Here $S A G$ stands for soil aggregate stability, $V C$ stands for vegetation cover while Width represents stream channel width and the subscripts 1 and 2 indicate treated and untreated riparian areas, respectively, while $\mu$ stands for the mean of the particular parameter.

To answer the above questions and address these hypotheses, the study (1) assessed surface soil aggregate stability (SAG), (2) stream width condition and (3) the state of vegetation cover along transects within the treated area inside the elk exclosure fence and in the untreated area downstream from the spring's origin. It was predicted that the restoration treatment and elk exclosure would provide more suitable conditions for the growth of wetland indicator plant species, such as Carex spp, improved soil aggregate stability and better stream conditions.

\section{METHODS}

In order to answer the research questions on the effects of the restoration practices, field measurements were taken on vegetation cover, soil aggregate stability (SAG), and stream width in both treated (site 1) and untreated (site 2) sections of the stream. Site 1 is located near the spring's source, and inside the elk-exclosure fence. Site 2 is downstream and on the other side of a forest service road, starting at approximately $66 \mathrm{~m}$ to the north of the road. A randomly selected starting point was established using a blind-flag toss, then the first plot was set up along the stream, perpendicular to the point where the flag landed. A measurement was taken at each starting plot using a geo-positioning system (GPS). A transect line was then extended to $120 \mathrm{~m}$, with a measurement plot directly parallel to the stream banks, located every $10 \mathrm{~m}$ on alternating sides of the stream channel for a sample size of $n=12$ plots for each treatment type. Measurement details on the three variables of interest are provided below.

\section{Vegetation Cover}

Ground cover was assessed in each plot using a $0.5 \times 0.5-\mathrm{m}$ quadrat. The location of the quadrats started at $0 \mathrm{~m}$, and then continued at $10-\mathrm{m}$ intervals along the stream bank so that a quadrat captures an area directly parallel to the stream's edge. Cover classes and plant species were recorded onto data sheets with the percent of the quadrat covered by each cover class or plant species type. The cover classes measured were: bare ground (complete absence of cover), rock (greater than 2"), litter (dead herbaceous plant matter), woody debris (dead woody plant matter), moss, and other specific plant species. The data from each treatment type were entered into an Excel spreadsheet and organized into matrices of rows of percent cover in each plot versus columns of plant species or other cover class. The mean percent cover of each class was then determined using the formula: \% cover for spp. $A=$ (total \% cover for spp. A in all plots/number of plots estimated) $\times 100$ (Unknown Author accessed from the webpages.uidaho.edu). The percent cover by class type or plant species was then put into pie graphs for visual representation and comparison of the data for the treated and untreated sites.

\section{Soil Aggregate Stability}

A Jornada field kit was used to assess the soil aggregate stability (SAG) of the surface soils along the stream. The procedure consists of collecting soil samples from each plot after vegetation cover data was collected. Six dry, pea-sized "pods" of surface soil were collected from each plot and put into sieves that were submerged in water and then dipped after 5 minutes of submersion. This was followed by assigning values from 1 to 6 to reflect the rate at which the soil pod "melted" away in the water. A value of 1 indicates very poor soil stability, 6 stands for the most soil stability value measured and the values in between represent gradual increases in the soil stability. The six SAG values for each plot were then averaged, and then the average of the 12 averages taken to determine the mean SAG value for each treatment type. A twosample T-Test with unequal variances was used with the R Console i386 3.0.2 to test for differences between the two data sets.

\section{Stream Width}

The width of the stream was also measured at 10 -m intervals along each transect. To measure the 
width of the stream, a metric transect tape was held by individuals at opposite edges of the stream and record the distance between them as the stream width in meters. The widths data were then analyzed using two-sample t-test statistics with unequal variances and plotted as a graph for visual interpretation and the results are discussed in the results section below.

\section{RESULTS}

Similar to methods, the analyses outcomes for the three different parameters are presented separately in this part. The three parameters, which are the bases for the three research hypotheses, are the degree of variability in vegetation cover, soil aggregate stability and stream width. The research outcomes related to each parameter are presented in some detail below.

\section{Vegetation Cover}

Vegetation and other cover classes and their respective percent area covered in the two treatment types (treated and untreated) are shown in Table 1. A special note from the cover class data is that there was the presence of Carex sp. in the treated site (in $15.5 \%$ of it), but not in the untreated site. Furthermore, there was more Bouteloua sp. or "grama" grass $(14.1 \%)$ in the untreated area compared to a $9 \%$ in the treated part. Elk scat/browsing evidence was also present in both treatment types; however, there was $33.33 \%$ of it in the treated area, and only very little $(0.167 \%)$ in the untreated site and within the elk-exclosure fence (see the last row of Table 1 and Figures 1 and 2). In spite of such differences in vegetation cover, there was no significant difference in bare ground and grass cover between the treated and untreated sites (see Figures 1 and 2).

\section{Soil Aggregate Stability (SAG)}

Soil aggregate measurements using Jornada field kit are analyzed with the R Console i386 3.0.2 to tests the differences in the SAG values between those of the treated and untreated plots. The mean

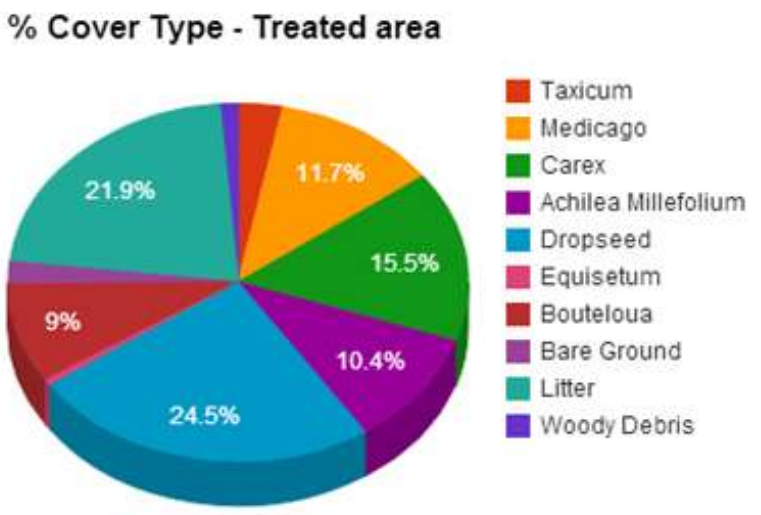

Figure 1. Percent of different Cover classes in the treated site.

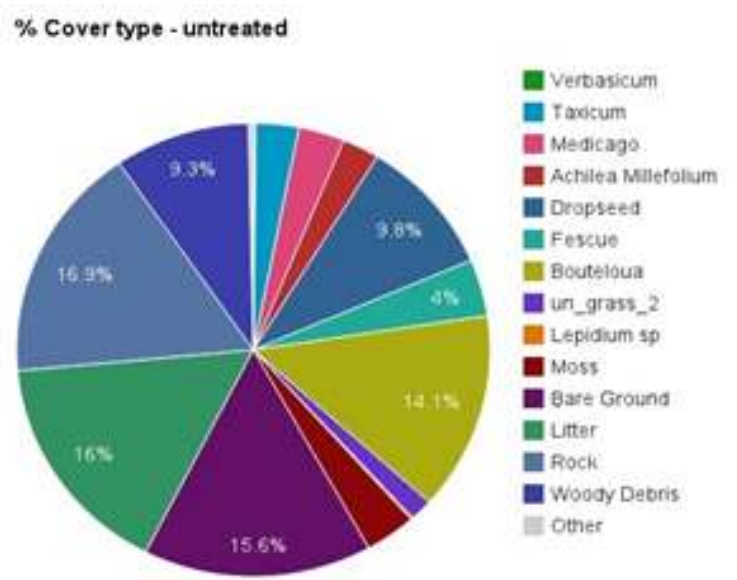

Figure 2. Percent Vegetation cover in untreated site; $\%$ Carex $=0$.

SAG values of the treated plots are 4.4 with a standard deviation of 0.737 , while those of the untreated ones are 2.4 with a standard deviation of 0.547 (see Figure 3). These values show that those of the treated plots are almost twice as much as those of the untreated ones with a p-value of $6.833 \times 10^{-8}$ (see Figure 3 ). This is very significant since the p-value is way less than the alpha value of 0.005 . Under this condition the null hypothesis is rejected in favor of the research hypothesis. This means, at the $95 \%$

Table 1. Cover survey results in treated and untreated areas.

\begin{tabular}{ll}
\hline Treated: & Untreated: \\
\hline $10.4 \%$ of area is bare ground & $15.6 \%$ of area is bare ground \\
Carex sp. observed as $15.50 \%$ of plant cover & There was a 0\% Carex sp. observed \\
& $\begin{array}{l}\text { Bouteloua } \text { sp. observed as } 14.1 \% \text { of cover } \\
\text { Bouteloua sp. observed as 9\% of plant cover }\end{array}$ \\
$\begin{array}{ll}\text { Evidence of browsing and elk scat observed in } \\
33.33 \% \text { of the plots inside exclosure }\end{array}$ & $\begin{array}{l}\text { Evidence of browsing and elk scat observed in } \\
\text { outside }\end{array}$ \\
\hline
\end{tabular}




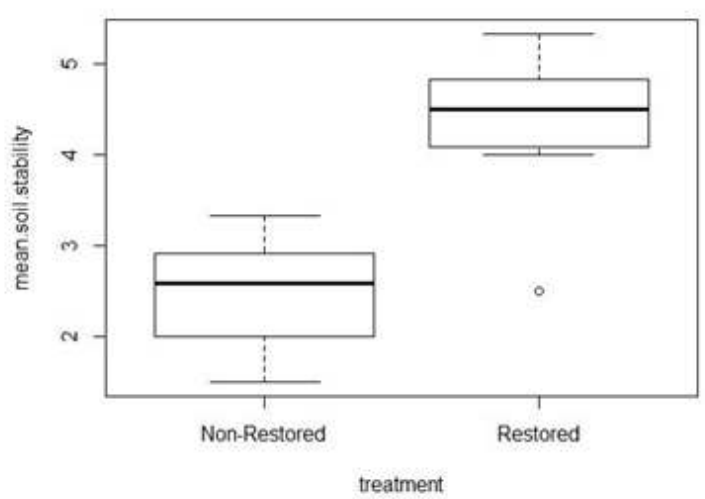

Figure 3. Mean Soil Aggregate Stability Values in treated and untreated plots.

confidence level, there is sufficient evidence from the data supporting the statement that the mean SAG value in the treated area was greater than the mean SAG value in the untreated area.

\section{Stream Width}

Two characteristic that are used to determine the stability and or vulnerability of a stream to change are stream width and depth. Generally the streams in the study area follow meandering paths as they flow away from the source springs. We used changes in stream widths as well as the presence or absence of water to compare the conditions in the treated and untreated watersheds. There was water in all of the treated plots, while water was absent in most of the untreated plots. Also as shown in Figure 4, the mean stream width in the treated site is $1.304 \mathrm{~m}$ with a standard deviation of 0.791 , while the mean stream width in an untreated site is $4.3 \mathrm{~m}$ with a standard deviation of 1.672. This means the mean stream width in the untreated plots is about three times as wide as that of the streams in the treated plots with a significance $\mathrm{p}$-value of $2.104 \times 10^{-5}<\mathrm{alpha}=0.05$ $(d f=15.688)(R$ version 3.0.2 (2013-09-25)).

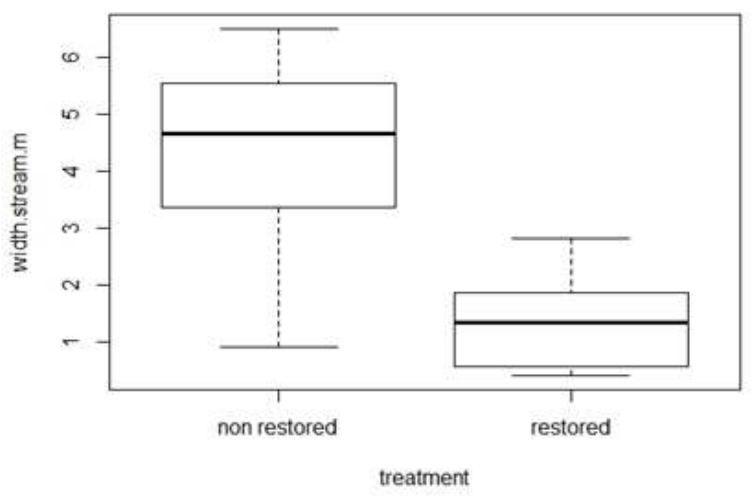

Figure 4. Graphical comparison of mean stream width values in treated and untreated areas.

\section{CONCLUSIONS}

Based on statistical analyses performed and from the R-output listed in the Results section above, several conclusions can be drawn on the observed data from the treated and untreated sites. The answers to our research questions on soil stability, vegetation cover characteristics, and changes in stream width in the system indicate that there are significant changes in the system. The soils in the treated area (site 1), on average, have become more stable, and contained Carex sp., while those in the untreated area, (site 2), did not have any sedges or wetland indicator species present. This indicates that the stream bank stabilization efforts were successful. However, the elk-exclosure fence does not appear to be effective in preventing ungulate activity in the treated area, as there was more evidence of browsing/elk activity within the fenced area than there was in the untreated and open area of site 2 (Bean 2012). Since there was little or no water present in the streams of site 2, while there was water along the entire transect in site 1, the elk may have been more attracted to the areas with drinking water and sweeter vegetation. The elk may have also preferred the treated area of site 1 more than the untreated areas of site 2 because of their relative locations. The untreated site 2 is located closer to a road and the "Elk Park Meadows" residential community to make it less secure and unsuitable for elks to freely graze. The fact that the elk-exclosure fence was cut by humans indicates that there is still a gap in awareness between field scientists and researchers implementing restoration projects and the less informed public. Furthermore, there was evidence of tire tracks along the edge of the meadow, an area in which motor vehicle access has been restricted. Also there are marks that show that a vehicle had been driven over/through the small wire fence near the site's entrance.

Watershed management goals in Arizona have included maintaining watershed health and ensuring the stability of fragile riparian ecosystems (Ffolliott et al. 2000). Restoration techniques of mechanical thinning, followed by pile burning would be an ideal preventative measure for land managers to take on the forest stands in the Lake Mary watershed. Thinning would not only reduce the fuels present in the system, but it would also reduce the loss of water due to evapotranspiration, and would leave more open space, water and nutrients for the remaining trees to grow healthier. If a wildfire were to occur in the ponderosa stands around Hoxworth Springs without some type of fuel reduction intervention, the effects on the stream vegetation and other riparian elements could be devastating. The situation would lead to watershed and stream bank erosion and the degradation of valuable springs in an area of freshwater scarcity. The problem is particularly important at a time of recurring drought, 
disappearing riparian areas and increasing water shortage. The importance of riparian areas can be summed up by their necessity to support up to $33 \%$ of the total flora and fauna in the Southwest even though they occupy only about $5 \%$ of the landscape in the area (Medina 1996, Phillips 2006). Considering that the most valuable and productive portions of land are the most at risk for degradation and loss of their functions, it is imperative that the public become better educated, more aware and take appropriate actions to help conserve and protect our local and regional riparian areas in particular and the overall health of the forest system surrounding them in general.

\section{REFERENCES}

BAKER, M. B. JR. 2003. Chapter 10 - Hydrology. pp. 161-174 in P. Friederici, ed., Ecological Restoration of Southwestern Ponderosa Pine Forests. Island Press, Washington D.C..

BEAN, T. 2012. Springs time in Flagstaff. $<$ http://azdailysun.com/news/local/springstime-in-flagstaff/article_68a4819d-8434-5226 -af2a-5c1d5297a7dd.html>. Accessed June 30, 2014.

BELNAP, J. 2003. The world at your feet: Desert biological soil crusts. Ecological Environments 1(5):181-189.

BROWN, D. 2008. A historical assessment of pronghorn management on Anderson Mesa: Miscalculations and remedies. In C.Van Ripper III and M. K. Fogge, eds., The Colorado Plateau III: Integrating Research and Resource Management for Effective Conservation. The University of Arizona Press. Tucson, AZ.

Cocke, A., P. Fule, and J. CROUSE. 2005. Forest change on a steep mountain gradient after extended fire exclusion: San Francisco Peaks, AZ, USA. Journal of Applied Ecology 42:814823.

FFOLLIOTT, P. F., M. BAKER., JR., C. B. EDMINSTER, M. C. DILlON, and K. L. MORA, tech. coords. 2000. Land Stewardship in the 21st Century: The Contributions of Watershed Management. Conference Proceedings, March 13-16, 2000, Tucson, AZ, RMRS-P-13, U.S. Department of Agriculture, Forest Service, Rocky Mountain Research Station Fort Collins, CO. 438 p.

MEDINA, A. L. 1996. Native aquatic plants and ecological condition of southwestern wetlands and riparian areas. Pp 329-335 in D. W. Shaw and D. M. Finch, tech. cords., Desired Future Conditions for Southwestern Riparian Ecosystems. Bringing Interests and Concerns Together. September18-22, 1995, Albuquerque, NM, General Technical Report RM-GTR-272. U.S. Department of Agriculture, U.S. Forest Service, Rocky Mountains Forest and Range Experiment Station, Fort Collins, CO.
PHILLIPS, F. 2006. Yuma East Wetlands Project: Restoring a Forgotten Landscape on the Lower Colorado. Yuma Crossing National Heritage Area. <http://www.fredphillipsconsulting.com/ pdf/yew_project_slide_show_2007.pdf> Accessed on 04/06/2014.

R FOUNDATION FOR STATISTICAL COMPUTING. 2013. Frisbee Sailing. R version 3.0.2 (201309-25. Platform: i386-w64-mingw32/i386 (32bit).

SPRINGER, A., D. ANDERSON, J. JANECEK, and L. DEWALD. 2005. Riparian Ecosystem restoration projects of the AWPF. Northern Arizona University. Accessed on 04/06/2014 at $<$ http://wrrc.arizona.edu/sites/wrrc.arizona.edu/ files/conf2005/presentations/Ecosystem \%20Restoration\%20in\%20AZ/Springer.pdf>

STEVENS, B. 2010. Wetlands drying up. Arizona Daily Sun 27 September 2010. <http://azdailysun.com/news/local/education/ wetlands-drying-up/article_64ffab38-f9f2-537 6-aff4-597b80f73626.html>

UNKNOWN AUTHOR. nd. Measuring plant cover. $<$ http://www.webpages.uidaho.edu/ range 357/notes/cover.pdf $>$. Accessed on 04/06/2014.

WEAVER, H. 1943. Fire as an ecological and silvicultural factor in the ponderosa pine region of the Pacific slope. Journal of Forestry 41(1):7-15. 